\title{
ОБУЧЕНИЕ СОЗДАНИЮ ВТОРИЧНЫХ ТЕКСТОВ ПО СПЕЦИАЛЬНОСТИ НА ЗАНЯТИИ ПО ИНОСТРАННОМУ ЯЗЫКУ В ВУЗЕ
}

\section{TRAINING (TEACHING) TO CREATE SECONDARY TEXTS IN SPECIALTY AT A FOREIGN LANGUAGE LESSON AT A UNIVERSITY}

\section{Zh. Demyanova}

Summary: The article deals with the issues of teaching students of non-linguistic faculties the basics of creating secondary texts. The article describes the effective and frequently used forms of forming an informative culture of processing text information in the process of working on a foreign-language text: annotation and abstracting. The basic principles of work in the process of annotation and abstracting are defined.

Keywords: foreign language, secondary text, annotation, abstracting, preparatory exercises.

\section{Актуальность}

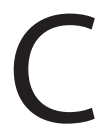
овременное общество называют обществом информационной культуры, в связи с этим способность обрабатывать информацию становится одним из ключевых необходимых навыков специалиста в любой сфере деятельности. В связи с этим, обучение работе над созданием вторичного текста при работе с текстом по специальности становится неотъемлемым компонентом содержания процесса формирования иноязычной коммуникативной компетенции в вузе.

\section{Проблема исследования}

Целью информативной обработки текста является не только его понимание, но и возможность трансформации в удобную форму в виде вторичного текста каковой является аннотация или реферат. Специалист сегодня должен обрабатывать большие объемы профессиональной информации не только на родном языке, но и на иностранном, английском языке, так как подавляющее число статей о последних достижениях науки во всех сферах написано именно на английском. Вместе с тем, как показывают исследования ученых и педагогов уровень иноязычной информативной культуры обработки текстовой информации у студентов неязыковых факультетов не соответствует запросам общества.

\author{
Демьянова Жанна Викторовна \\ к.п.н., дочент, Начиональный исследовательский \\ университет «МЭИ», г. Москва \\ dem.zhann@mail.ru
}

Аннотация: В статье рассматриваются вопросы обучения студентов неязыковых факультетов основам создания вторичных текстов. Охарактеризованы эффективные и часто используемые формы формирования информативной культуры обработки текстовой информации в процессе работы над иноязычным тексом: аннотирование и реферирование. Определены основные принципы работы в процессе аннотирования и реферирования.

Ключевые слова: иностранный язык, вторичный текст, аннотирование, реферирование, подготовительные упражнения.

Извлечение полезной информации иноязычного текста и передача этой информации в сжатой и понятной форме вызывает трудности у большинства студентов.

Цель данного исследования - охарактеризовать основные виды информативной обработки текстов для успешной профессиональной деятельности - аннотирование и реферирование и сформулировать основные принципы работы при обучении аннотированию и реферированию студентов неязыковых факультетов при обучении иностранному языку в вузе. Автор излагает свой взгляд на проблему и описывает ее возможные решения.

\section{Изложение основного материала}

Работая со специальной литературой (профильные тексты, научные статьи, монографии, отраслевые справочники, отраслевые журналы, каталоги, стандарты, инструкции и другими) специалисту необходимо не только ориентироваться в содержании, но и овладеть искусством информативной обработки исходных, то есть первичных текстов. Целью информативной обработки текста является извлечение полезной информации текста и передача этой информации в сжатой и понятной форме [5, с. 89]. Ко вторичным текстам в прикладной лингвистике относят библиографическое описание, аннотацию, реферат, конспект, перевод и рецензию. 
Наиболее эффективными и часто используемыми формами формирования информативной культуры обработки текстовой информации в процессе работы над иноязычным тексом являются аннотирование и реферирование, но часто эти формы работы с иноязычным текстом вызывают у большинства студентов серьёзные трудности [5, с. 91].

Такая работа требует подготовки как студента, так и преподавателя. (преподаватель - отбор текстов (актуальность, доступность).

Аннотирование и реферирование любого текста предполагает, прежде всего, его анализ с точки зрения различных аспектов: герменевтического, лингвистического, экстралингвистического, стилистического, коммуникативного.

Герменевтический аспект означает понимание текста. Важным моментом здесь является то, что прежде всего студенты должны уметь различать тему текста и идею, которые во многих случаях могут быть совершенно разными.

Лингвистический аспект анализа текста предполагает понимание особенностей его кода (языка). При анализе научного или научно-публицистического текста следует обратить внимание на ряд его лингвистических особенностей: 1) использование определенной лексики и клише, которые могут как составлять стиль данного текста, так и дополнять его коммуникативное сообщение; и 2) использование определенных грамматических структур, свойственных разным видам текста.

Экстралингвистический аспект также может оказаться очень важным. Следует обращать внимание не только на географические названия или имена людей, но и на идеи (понятия, теории, смыслы). К подобным вещам представители разных культур могут относиться поразному. Необходимо обращать особое внимание на исторические и культурные связи, а также на ассоциации, которые они могут вызвать.

Стилистический аспект предполагает анализ текста с точки зрения трех основных направлений стилистики: 1) стилистическая семасиология, которая исследует стилистические явления в сфере семантики, т.е. в сфере значений, независимо от формы языковых единиц; 2) стилистическая лексикология, которая предполагает, что слова, относящиеся к особым сферам языкового общения, обладают некоторым собственным фиксированным стилистическим оттенком и, независимо от контекста, обнаруживают свою привязанность к той или иной лингвистической сфере; 3) стилистический синтаксис, определяющий стилистическую ценность синтаксических форм, стилистические функции синтаксических яв- лений, их стилистические классификации.

Коммуникативный аспект заключается в понимании смысла текста, то есть идеи, стоящей за словами, цели автора. Чтобы правильно понять его, необходимо принять во внимание все неявные значения, а также коммуникативную ситуацию в целом.

А.А. Вейзе определяет реферат как сжатое изложение основного содержания исходного текста при сохранении его семантической цельности [2, с. 100].

Рефераты относят к сокращенным и усеченным текстам, в то время как аннотации причисляют к скомпенсированным текстам [6, с. 130].

На первом занятии при обучении реферированию преподаватель должен объяснить студентам основные отличия реферата и аннотации.

Основным отличием языка реферата от языка аннотации является то, что аннотация лишь сообщает, какие вопросы освещает первоисточник, реферат же информирует о том, что изложено по каждому из затронутых вопросов $[7$, с. 56].

Кроме того, в аннотации основные аспекты тематики первоисточника передаются своими словами, представляющими высокую степень абстрагирования и обобщения. В реферате же формулировки и обобщения заимствуются из самого текста оригинала, при этом при написании реферата допустимо сложные предложения преобразовывать в простые, широко используются неопределенно-личные предложения.

Реферат должен быть некритичным информационным резюме (кратким изложением), содержащим суть и собственные выводы статьи [1, с. 128]. Реферат может содержать графические скрепы/опоры (рисунки, схемы, чертежи и другое) исключительно с целью отражения содержания первоисточника и сокращения его объема. При написании реферата необходимо избегать таких ошибок, как потеря информации, дублирование, искажение и нарушение смысла, нарушение стиля.

Различают реферат-обзор, который представляет собой обзор нескольких источников и составляет 10-15 страниц, реферат-резюме - краткое изложение статьи, целой книги или ее части и составляет 1-2 страницы и реферат-аннотация - сжатое изложение статьи, курсовой, дипломной работы (объем порядка 10-12 строк).

Среди аннотаций различают справочные (подругому - информационные или описательные) - цель которых дать самую общую характеристику первоисточника; рекомендательные - характеристика документа и рекомендации по его использованию; аналитические - 
направленные на анализ первичного текста содержащих информацию по конкретной проблеме; общие - рассчитанные на широкую группу читателей; и специализированные - нацеленные на узкий круг специалистов [3, с. 20].

Ключевые стереотипные фразы (клише) для аннотирования и реферирования необходимо разобрать на вводном занятии перед первым аннотированием или реферированием.

В качестве подготовительных упражнений к аннотированию и реферированию можно использовать такие задания как: 1) перевод на основе использования подстановочных таблиц с использованием стереотипов (клише), 2) выделение пунктов логического плана, 3) выделение ключевых слов и предложений (key-words|keysentences), 4) выделение главной мысли абзаца, 5) упрощение сложных предложений, 6) озаглавливание текста, 7) составление терминологического глоссария (вокабуляра) к тексту с использованием двуязычного или многоязычного словаря, 8) работа с одноязычными вопросно-ответными упражнениями, стимулирующими употребления определенных речевых стереотипов [4, c. 173].
Если статья сложная, в дополнении к обычному плану можно воспользоваться приемом картирования (mindmapping) или составить глоссарий к тексту.

На первом занятии целесообразно выполнить реферирование одинаковой статьи. В дальнейшем статьи могут быть разными в зависимости от уровня иноязычной компетенции конкретного студента.

Чтобы работа над реферированием и аннотированием была максимально эффективной преподавателю необходимо учитывать основные принципы отбора текста для информационной обработки, а именно: актуальность, доступность, аутентичность.

Таким образом, мы проанализировали аннотирование и реферирование как основные формы формирования информативной культуры обработки текстовой информации в процессе работы над иноязычным текстом. Мы выявили основные принципы работы с вторичными текстами которые, несмотря на возникающие трудности, помогут сделать эффективным обучение аннотированию и реферированию иноязычного текста на занятиях по иностранному языку.

\section{ЛИТЕРАТУРА}

1. Буран А.Л. Вестник Томского государственного педагогического университета. 2013. № 7 (135). C. 127-130. URL: https://cyberleninka.ru/article/n/ obuchenie-studentov-neyazykovogo-vuza-osnovam-sozdaniya-vtorichnyh-tekstov-pri-chtenii-inoyazychnoy-literatury-po-spetsialnosti/viewer

2. Вейзе А.А. Реферирование текста. Минск: Изд-во Белорус. гос. ун-та, 1978. 128 с.

3. Князева Е.Г. Информационная обработка текстов. Учебное пособие - М., 2001. 43 с.

4. Маркушевская Л.П., Ермолаева С.А. Научно-технический вестник Санкт-Петербургского государственного института точной механики и оптики (технического университета). 2003. № 7. С. 172-175. URL: https://cyberleninka.ru/article/n/metodika-obucheniya-referirovaniyu-i-annotirovaniyu-na-zanyatiyah-poinostrannomu-yazyku/viewer

5. Назаренко Т.Ю. Общество: социология, психология, педагогика. 2014. № 1. С. 88-91. URL: https://cyberleninka.ru/article/n/referirovanie-inoyazychnyhtekstov-kak-sredstvo-formirovaniya-kommunikativnoy-kompetentsii-molodogo-spetsialista/viewer

6. Провоторов В.И. Аннотирование и реферирование как методические приемы в обучении работе над специальными текстами

7. Ученые записки. Электронный научный журнал Курского государственного университета. 2006. № 2. С. 129-135. URL: https://cyberleninka.ru/article/n/ annotirovanie-i-referirovanie-kak-metodicheskie-priemy-v-obuchenii-rabote-nad-spetsialnymi-tekstami/viewer

8. Якутина, 0.Л., Лупу, Е.В. Я 49 Обучение реферированию и аннотированию на иностранном языке (английском, немецком): учебно-методическое пособие для бакалавров, магистров и аспирантов всех направлений подготовки / 0.Л. Якутина, Е.В. Лупу. - Смоленск: ФГБОУ ВО Смоленской ГСХА, 2018. - 84 с. 